\title{
Interobserver variability of myocardial T1 and T2 mapping in patients with suspected myocarditis
}

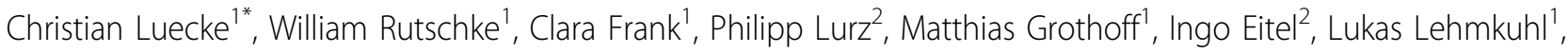
Holger Thiele ${ }^{2}$, Matthias Gutberlet ${ }^{1}$

From 17th Annual SCMR Scientific Sessions

New Orleans, LA, USA. 16-19 January 2014

\section{Background}

The aim of this study was to test the interobserver variability of myocardial T1 and T2 Mapping prior to and T1 Mapping after the administration of contrast agent in patients with suspected myocarditis. The estab- lished methods for the detection of the presence of active inflammation - edema ratio (ER) and global relative enhancement (gRE) - require a "normal" reference region of interest (ROI) in adjacent skeletal muscle and depend on the choice of the muscle as well as its outline

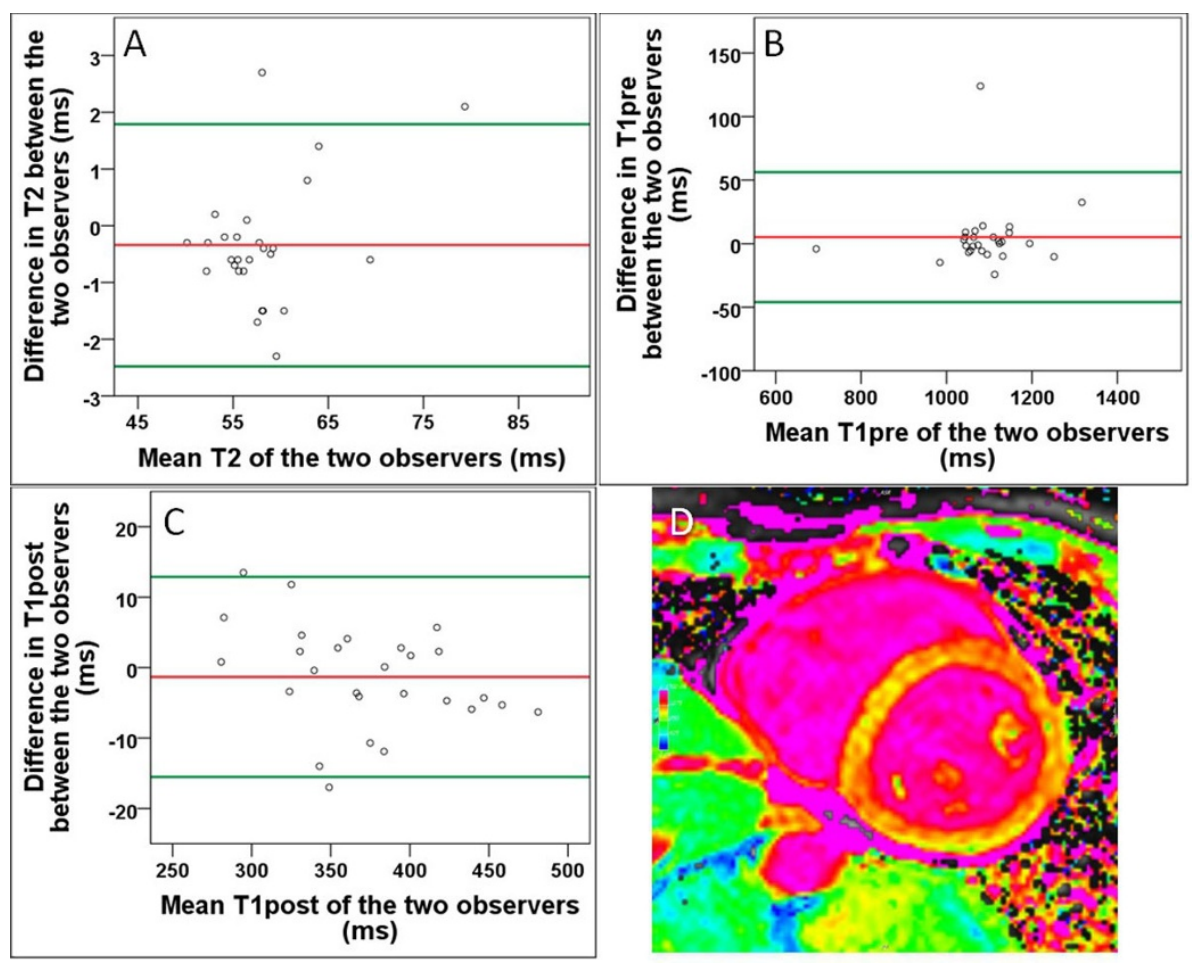

Figure 1 Bland-Altman Analysis of global myocardial T2 (A) and T1 times before (B) and after (C) the administration of contrast agent Example of a T1 map before administration of contrast agent (D).

'Diagnostic and Interventional Radiology, Heartcenter Leipzig, Leipzig,

Germany

Full list of author information is available at the end of the article

(c) 2014 Luecke et al.; licensee BioMed Central Ltd. This is an Open Access article distributed under the terms of the Creative Commons 
which can lead to high interobserver variability. Mapping techniques offer a quantitative approach without the need of a reference region.

\section{Methods}

27 patients (17 male, 10 female; mean age, $49 \pm 19$ years) with clinically suspected myocarditis underwent Cardiovascular Magnetic Resonance Imaging (CMR) at $1.5 \mathrm{~T}$ (Gyroscan Intera CV, Philips Medical Systems, Best, the Netherlands). The CMR assessment included midventricular single slice $\mathrm{T} 1 \mathrm{maps}$ before (T1pre) and after (T1post) the administration of contrast agent ( $\mathrm{TR}=2,75$ $2,9 \mathrm{~ms}$, TE $=1,38-1,45 \mathrm{~ms}$, TI $=168-6659 \mathrm{~ms}$, slice thickness $=10 \mathrm{~mm}, \mathrm{FOV}=380 \times 380 \mathrm{~mm}$, Matrix $=320 \times$ 320 ) and T2 maps (T2) without contrast (TR $=545,45$ $1200 \mathrm{~ms}, \mathrm{TE}=11,66-48,27 \mathrm{~ms}, \mathrm{TI}=250 \mathrm{~ms}$, slice thickness $=8 \mathrm{~mm}$, FOV $=370 \times 370 \mathrm{~mm}$, Matrix $=384 \times$ $384)$ in short axis orientation. Interobserver correlation and Bland-Altman-analysis was performed.

\section{Results}

The interobserver agreement was high in T1pre, T1post and T2 mapping sequences $(r=0,97, r=0,99$ and $r=$ 0,98 , respectively) and showed only small interobserver bias (bias T1pre $=5,1 \mathrm{~ms}$, bias T1post $=-1,3 \mathrm{~ms}$ and bias $\mathrm{T} 2=-0,3 \mathrm{~ms}$ ) with narrow limits of agreement (LOA T1pre $=-45,9$ and $56,2 \mathrm{~ms}$, LOA T1post $=-15,5$ and 12,9 $\mathrm{ms}$ and LOA T2 $=-2,5 \mathrm{~ms}$ and $1,8 \mathrm{~ms}$, (Figure 1 ). The variation coefficient was lowest for T1post (9.5\%) and T2 (9.9\%) and low for for T1pre (14\%).

\section{Conclusions}

Myocardial T1 Mapping prior to and after the administration of contrast agent and myocardial T2 Mapping show very low interobserver variability and could be observer independent tools to evaluate patients with myocarditis by CMR. The relative limits of agreement were with $2 \%$ of the mean narrow for all three mapping sequences.

\section{Funding}

None.

\section{Authors' details}

${ }^{1}$ Diagnostic and Interventional Radiology, Heartcenter Leipzig, Leipzig, Germany. ${ }^{2}$ Internal Medicine/Cardiology, Heartcenter Leipzig, Leipzig, Germany.

Published: 16 January 2014

doi:10.1186/1532-429X-16-S1-P249

Cite this article as: Luecke et al: Interobserver variability of myocardia

$\mathrm{T} 1$ and T2 mapping in patients with suspected myocarditis. Journal of

Cardiovascular Magnetic Resonance 2014 16(Suppl 1):P249.

\section{Submit your next manuscript to BioMed Central} and take full advantage of:

- Convenient online submission

- Thorough peer review

- No space constraints or color figure charges

- Immediate publication on acceptance

- Inclusion in PubMed, CAS, Scopus and Google Scholar

- Research which is freely available for redistribution 